\title{
Unconventional Opposition in Discourse: From the Perspective of Systemic Functional Linguistics
}

\author{
Wenxiu Song \\ School of Foreign Languages \\ Southwest University of Political Science and Law \\ Chongqing, China \\ E-mail: viviansong1@163.com
}

Received: April 10, 2019 Accepted: September 2, 2019 Published: December, 30, 2019

doi:10.5296/jsel.v8i1.16159 URL: https://doi.org/10.5296/jsel.v8i1.16159

\begin{abstract}
Writers construct two entities or events as opposites in specific context by using language resources realizing semantic opposition, such as antonyms, parallel structure and conjunction for adversity. The construction of such temporary opposites (unconventional opposition) facilitates the presentation of writer's stance and strengthens the interaction between the writer and readers. From Systemic Functional Linguistics, this study analyzes the ideational, interpersonal and textual meaning of unconventional opposition in discourse. It is found that the insertion of the opposite participants and process types in the current field contributes to demonstrate the ideational meaning of the discourse topic more fully, thus facilitating readers' understanding; in the respect of interpersonal meaning, the opposite meaning triggered by negation can exclude the readers' possible expectations while that triggered by attitudinal resources helps to negotiate appraisal meanings with readers, that is, affect, judgment of social behavior or appreciation of product; in the sense of textual meaning, unconventional opposition assigns a reader-friendly text structure, information flow and cohesion mechanism.
\end{abstract}

Keywords: semantic opposition, unconventional opposites, Systemic Functional Linguistics, metafunctions 


\section{Introduction}

Language not only reflects the external world and individual experience, but also actively constructs the world and experience in human's mind. Similarly, semantic opposition is not only reflected in language resources such as antonyms but also can be constructed through resources of opposite meanings by writer to express his/her stance and views.

According to Jeffries (2010) and Davies (2013), oppositional relation constructed in specific textual surroundings between pairs of entities/ events which are not opposite in meaning is termed 'temporary opposites', 'constructed opposites', 'textual opposites', 'unconventional opposites' or 'created opposites'. ('unconventional opposites' is adopted in this study). The writer usually employs the language resources embodying semantic opposition, namely, the opposition triggers, to place two entities or events which do not opposite to each other into oppositional relation, which is a process involving context, writer's motivation and reader's expectation, and also a kind of language use driven by motivation. As a process of re-representation of meaning, how opposition triggers work in the context is worth exploring from within the language system.

Rather than paying much attention to the ideal and formal syntactic structure, Systemic Functional Linguistics regards language as a social semiotic system and lays stress on 'language in use' in context. Therefore, it is undoubtedly an effective theory for the study of meaning-making of unconventional opposition in discourse.

\section{Theoretical Framework}

According to Halliday (1985), language can be used to construe experience, build social relations and weave together of these two functions to create text, which is the so-called three metafunctions of language: ideational function, interpersonal function and textual function. Halliday $(1985,1994,2004)$ systemically expounds the grammar system through which the metafunctions of language are realized. The functional grammar he proposes primarily explores how the above three kinds of meanings are presented in grammatical structure on the level of clause. Martin and Rose (2007) extend the operation of grammar system of language metafunctions to the level of discourse.

Ideation deals with how human experience is construed in discourse. Thompson (2000) proposes that ideational function is further divided into experiential function and logical function. The former refers to the grammatical choices that enable speakers to make meanings about the world around us and inside us, which is illustrated by transitivity system. As to the logical function, Halliday $(1985,1994)$ describes it as those systems 'which set up logical-semantic relationships between one clause to another'. He explores the language units in the clause and relations between clauses grounded in their interdependency and logical-semantic relations. Martin and Rose (2007) develop the ideational function on the level of text, holding that lexical relations (semantic relations) between the particular people, things, processes, places and qualities that build the field of a text constitute the system of IDEATION. Furthermore, three sets of lexical relations are identified in ideation system, 
namely, taxonomic relations, nuclear relations as well as activity sequences (see figure 2 below).

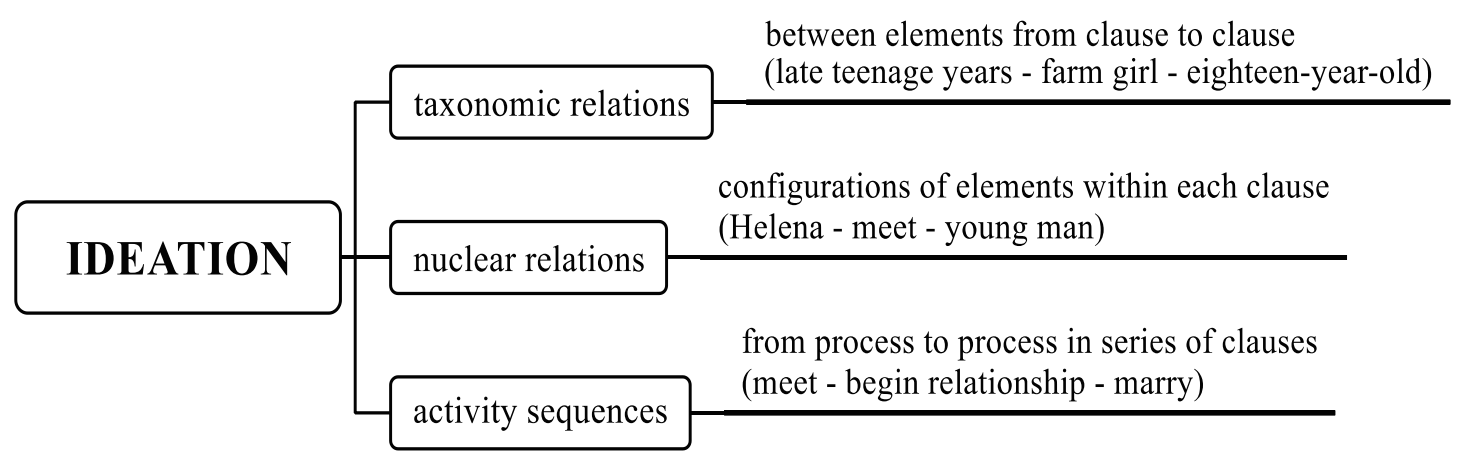

Figure 1. Ideation system (Martin \& Rose 2007: 75)

Interpersonal function, as the participation function of language, refers to the meaning potential in which the speaker is regarded as intruder (Hu et al, 2008: 115). By virtue of interpersonal function of language, people establish interpersonal relationship, express their opinions, attitudes and emotions, and it also reflects the relationship between and status of the communicators. In Halliday's functional grammar $(1985,1994)$, mood and modality are used to realize interpersonal function. The interpersonal meaning in functional grammar are studied more fully and comprehensively since Martin's establishment of appraisal theory which focuses on lexical resources of interpersonal meaning from discourse semantics (Martin, 2001, 2005). Appraisal theory examines the linguistic resources by which writers express, negotiate and naturalize particular inter-subjective and ultimately ideological positions (Hu, 2008: 318), including three subsystems: attitude, engagement and graduation.

Textual function, also known as 'enabling' function, contributes to organize stretch of spoken or written discourse into a coherent and unified text (Hu, 2008: 161), and it is realized by thematic structure, information structure, lexical cohesion and grammatical cohesion. Halliday (1994: 37) states that theme is the element which serves as the starting point for the message and categorizes the remainder of the message, the part in which the theme is developed, into rheme. In addition, if the theme of a clause expressing message is consistent with subject, the theme is unmarked one. However, when the theme is not the subject of the clause, the theme is marked. As far as Halliday is concerned (1994), the speaker is obliged to organize his speech into information units. The internal organization of the information unit relates to the way in which given and new information is distributed within the unit. Characteristically, he suggests that the speaker will order given information before new information. The unmarked sequencing of information structure is taken to be given-new. Naturally, information units which are initial in a discourse will contain only new information. Mathesius (1939) of Prague School assumes that theme generally carries given information while rheme transmits new information. The writer may choose the marked theme as the 
point of departure for message or the new information as the theme, for particular purpose. The most widely accepted definition of cohesion as a linguistic concept comes from Halliday and Hasan (1976: 4), that is, cohesion refers to relations of meaning that exist within the text and falls into grammatical cohesion and lexical cohesion. It is by virtue of cohesion that meanings of phases are connected and organized as an organic entity, specifically, a text. In the framework of Systemic Functional Linguistics, this study explores the meaning-making of unconventional opposition from three dimensions: ideational, interpersonal and textual meaning.

\section{Ideational Meaning of Unconventional Opposition}

According to the development of ideational meaning in discourse by Martin and Rose (2007), each sentence in a paragraph revolves round a topic, with taxonomic relations, nuclear relations as well as activity sequences working together to form a field of experience focusing on this topic. The writer of the text inserts a process or participant which is made opposite to the topic by opposition trigger and foregrounded in the field of experience. It is the key to uncover the ideational meaning of unconventional opposition that explore how the introduced opposite operates in the field of experience of the current text and how it relates to the three semantic categories, that is, action process, participant and circumstantial elements.

\subsection{Unconventional Opposition and Process Type}

In functional grammar, action process is the core element of transitivity system's construal of human experience. Our experience of reality is captured in terms of processes (or 'goings-on') happening, doing, sensing, meaning, being and becoming, which constitute the transitivity system of language (Halliday, 2010). Halliday believes that the transitivity system construes the world of experience into a manageable set of process types (Halliday, 2010). With the help of opposition trigger, writer brings a process type into the current field of experience and constructs the brought process and the process of main clause as opposites. The inserted opposite process is foregrounded as its ideational meaning is concerned. Besides, it forms a logico-semantic relation (expansion) with the main clause, by providing the information about location, circumstance, cause, etc. For example:

Example 1: He became very quiet. Withdrawn. Sometimes he would just press his face into his hand and shake uncontrollably. I realized he was drinking too much. Instead of resting at night, he would wander from window to window. He tried to hide his wild consuming fear, but I saw it. (Martin \& Rose, 2007: 31).

In example 1, the text chiefly represents the field of experience of 'he', with 'he' and his body parts as the primary participants. As for the action sequence, the attribute of 'he' is first shown in the intensive attributive relational process become, followed by the material process elaborating the attribute of quiet by press, shake and drink. Before generalizing the emotional states of the participant by fear finally, the writer introduces the opposite resting at night through the opposition trigger instead of embodying negation to constructs a temporary semantic opposition to wander from window to window in the main clause. The inserted 
process is involved in forming a logico-semantic relation (expansion) with the main clause by adding new information to develop the meaning of the main clause. Specifically, the circumstantial element at night in the inserted process resting at night provides more semantic information for wander from window to window in the main clause. Rest is not only opposite to wander in the main clause, but also to the process in the whole experience field, with its ideational meaning being foregrounded. That is to say, in the process of the writer's construction of opposition, the semantic opposition generated by the creation of a particular context and the added circumstantial elements help to spotlight the topic and bring out the dreadful anxiety of 'he'.

\subsection{Unconventional Opposition and Participant}

Words that trigger unconventional opposition in the context by virtue of their inherent semantic oppositions, can be term 'metalinguistic trigger of opposition', such as differ, contrast, distinguish, oppose, etc. In a discourse on a particular topic, entity opposite to the topic can be inserted with the support of metalinguistic trigger of opposition. In such a context of unconventional opposites, the opposition trigger, topic and the inserted entity are involved into a transitivity system and work together to form a relational process, in which the topic serves as the carrier and the inserted participant concerns with the attribute of the topic. For example:

Example 2: Hence, our findings contrast with the general conception in the literature that speaking is the most anxiety-provoking activity (Xiao \& Wong, 2014: 606).

Example 3: While the third occurrence of creak in line 17 also marks a parenthetical, it is distinguished from the two preceding examples. (Lee, 2015: 292)

In example 2, contrast with triggers the opposition between our findings and the general conception; in example 3, distinguish from triggers the opposition between third occurrence of creak and the two preceding examples. The writer inserts new participant the general concept / the two preceding examples into the field of experience about our findings/ third occurrence of creak, with the metalinguistic trigger of opposition, topic of the discourse and the inserted entity working together to constitute a relational process realized by attributive clause. The inserted entity describes and categorizes the attribute of the discourse topic. Although such attribute opposite to the carrier is not part of the experience field of the current topic, it is familiar to the readers, such as the general conception in example 2, or the entity mentioned and discussed above like the two preceding examples in example 3 . Such a contrast between the carrier and attribute together with readers' higher familiarity with the attribute facilitate readers' understanding of the topic (carrier).

\subsection{Unconventional Opposition and Circumstantial Element}

Halliday (1994: 151-152) believes that circumstance is the supplementary of the process, providing time, location, manner and cause of the process. It is a kind of additional minor process, subsidiary to the main one, extending, explaining and illustrating the main process. Nevertheless, it embodies some of the features of a relational or verbal process, and thus introducing a further entity as an indirect participant in the clause. In a certain context, the 
metalinguistic triggers of opposition such as phrases in contrast to, as opposed to and negative words or phrases such as unlike, rather than introduce a participant into the current field. Such a process of constructing unconventional opposition changes the transitivity system of the proposition representation by supplementing it with circumstantial elements. For example:

Example 4: Unlike Facebook, these social network connections are unidirectional, so that celebrities may have millions of followers. (Eisenstein, 2015: 168)

Example 5: In contrast to the long-standing concept of motivation in second language acquisition, investment acknowledges that a language learner has a complex social identity and multiple desires, and takes into account the power inequities inherent in social context. (Palmer et al., 2014: 762)

Example 6: As opposed to Extract 7, Carlos this time seems to notice the presence of "from" as indicated by his repetition. (Eskildsen \& Wagner, 2015)

In example 4, Facebook is brought in through the employment of negative preposition unlike, which is parallel to the subject these social network connections in main clause; in example 5, the metalinguistic trigger of opposition in contrast to introduces the participant the long-standing concept of motivation, which is parallel and opposite to the investment in main clause; in example 6, the phrase as opposed to, an metalinguistic trigger of opposition, inserts Extract 7, which is parallel to this time in main clause. The realization of unconventional opposition by language changes the transitivity system of main clause, by introducing circumstantial elements about manner or expressing contrast, and adding new participant to the main clause.

The added participant is either a thing more familiar to the readers in a certain cultural context, such as Facebook in example 4, or concept that readers are expected to be familiar with, like the long-standing concept of motivation in example 5, or concept mentioned above such as Extract 7 in example 6. Such added circumstantial elements further develop the main process in that for one thing, they provided more detailed semantic complements such as location, time, manner and cause for the main process; for another, the opposition triggers construct an oppositional relation between the added participant and the parallel participant in main clause. Readers can understand the relevant information of the main clause more easily, owing to the added semantic information and the constructed unconventional opposition and more importantly, the greater familiarity with the inserted participants of the readers. Nevertheless, it should be noted that in some contexts, the inserted opposite may have never been mentioned above or/ and be unfamiliar to the readers. For example:

Example 7: Self- repair was defined as self- initiated, self-directed talk, rather than collaborative interaction. (Bowles et al., 2014: 506)

In example 7, the opposite collaborative interaction is introduced by rather than, forming an oppositional relation with self-initiated and self-directed talk. The readers are expected to hold that self-repair was defined as collaborative interaction and therefore, in order to draw the readers over to his side, the writer inserts a new participant collaborative interaction and 
keeps it opposite to the current topic to guide the readers by excluding their possible expectations.

\section{Interpersonal Meaning of Unconventional Opposition}

The interpersonal meaning of constructing unconventional opposition in a text is found in two aspects: first, the interweave of constructed opposition and modality system; second, the promotion of interaction between writer and readers by appraisal resources through acting as opposition triggers.

\subsection{Unconventional Opposition and Modality System}

In the complementary opposites, to deny one means to affirm the other. That is to say, the meaning of the negative expression of a proposition is equal to that of the positive expression. For example, the meaning of the president is a woman is equal to the president is not a man. Therefore, it will be redundant if the positive and negative expression of the same meaning concur in a sentence. In some discourses, the write negates an entity or event with a negative structure or a negative word or phrase and then corrects it, thus raising an unconventional opposition between the two entities or events. Underlying motivation of the writer can be detected in such context in which negation and affirmation co-occur.

Example 8: Love looks not with the eyes, but with the mind. (Shakespeare, 2003:19)

As the saying goes, the eye is the window of the mind, which reveals the similarity relation between eye and mind rather than oppositional relation. However, in example 8, unconventional opposition between eye and mind is constructed in the peculiar context created by negative structure not and conjunction but as well as the employment of parallel structure. Constructing opposites by negative structure to convey a proposition that can be clarified by a positive proposition, far from being redundant, expresses the writer's stance more clearly.

In functional grammar, as one of the ways to realize interpersonal meaning, affirmation and negation are parts of polarity system which refers to the choice between positive and negative as in is/isn't, do/don't. In English, polarity is realized typically by Finite element; each finite verbal operator has two forms, one positive, the other negative (Halliday, 1994: 88). However, there are many possibilities rather than only one choice for the writer to evaluate his proposition. In the proposition for communicating information, there are intermediate degrees that fall in between the positive and negative poles, realized by the probability and frequency of modality (Halliday, 1994: 89). Furthermore, preference for the positive is found in discourse, specifically, positive probably works out around ten times as frequent as negative (Halliday \& James, 1993). Such a kind of markedness of the negation shapes its special pragmatic features in the text: first, negation is capable of triggering presupposition (Givón, 1993: 188). In example 8, the use of the negative structure presupposes the existence of the positive proposition, that is, the most popular saying about love- 'love at first sight'. Secondly, negation is interactive, to be specific, when a speaker negates proposition, it means 
that not only does he believe that the proposition is false, but he also supposes that the readers may believe that the proposition is true (Miao, 2011: 223). In the above example, the speaker thinks that 'love comes from appearance (the beauty of the other side)' is improper and meanwhile, he expects the readers have attached importance to appearance in love. Therefore, Shakespeare negates the readers' expectation before giving his positive assertion, to ultimately express his stance more specifically in the interaction with the readers.

\subsection{Unconventional Opposition and Appraisal System}

Opposition is typically dichotomous and therefore, opposition in ideology involves necessarily such positions and evaluation implying dichotomy as our side/ other side, good/ bad, right/ wrong and so on. Appraisal theory examines the linguistic resources by which writers express, negotiate and naturalize particular inter-subjective and ultimately ideological positions (Hu, 2008: 318), with a particular stress on attitude system. Divided into several categories, the whole attitude system overflows with dichotomy, such as explicit/ implicit, positive/ negative, and happiness/ unhappiness, security/ insecurity, satisfaction/ dissatisfaction in AFFECT. Therefore, the dichotomy that opposition and evaluation have in common provides a theoretical basis for the generation of interpersonal meaning of the unconventional opposition.

Lying at the heart of attitude system is Affect, by which the writer resonates emotionally with readers and consolidates the solidarity with the them. In example 1, quiet is employed to present the emotion of he, then withdrawn. Before evaluating the extremely negative emotion of he as wild consuming fear, resting at night is introduced into discourse by phrase of negative meaning instead of, thus constructing unconventional opposites resting at night and wander from window to window. In addition, negative emotions pervade the whole discourse and graduation system is involved in the evaluation of the leading character's emotion variation, specifically, from vey to wild consuming. In the constructed opposition, the regular life of normal people (resting at night) is introduced to be opposite to wandering at night, serving as an implicit means of evaluation to evoke the emotion of the readers. Therefore, the construction of opposition is conducive to the negotiation of the affect between the writer and the readers, and promotes readers' understanding of and sympathy with the pain of the leading character in the discourse.

Judgment intends to evaluate human behaviors by reference to a set of institutionalized norms. However, there is no definite standard to judge whether a certain behavior is moral, legal or normal considering the cultural and individual differences. The writer will resort to constructing unconventional opposition and shuffle off the responsibility of position-taking onto readers when judging divergent behaviors.

Example 9: Charles, unskillfully, is playing for the popular vote; Diana, very skillfully, is doing the same. (Jones, 2002: 49)

In example 9, the writer constructs the behaviors of Princess Dianna and Prince Charles as opposites by employing antonyms as triggers, increasing the meaning potential of the antonym unskillfully/ skillfully to express the judgment of social behaviors. Antonyms are 
important lexical resources that trigger opposition, as is found in Jones's (2002) study on antonyms based on corpus that the primary textual function of antonym is to trigger opposites formed by another pair of language units. The semantic opposition between the antonyms unskillfully and skillfully triggers the opposition between Charles and Dianna. The oppositional relationship between Charles and Diana cannot be fully understood if unskillfully and skillfully are viewed merely from lexical semantic relation. The antonym unskillfully/ skillfully implies the writer's evaluation of Prince Charles and Princess Diana in striving for the popular vote, in other words, the social behaviors of the members of British royal family (Attitude-Judgment-Social Esteem), which reflects their social influence. This constructed opposition is not an innovative product of the writer given that it is well-known in English cultural context that Charles and Dianna were at odds at that time. However, the popular vote-getting bid is such a social behavior without unified standard that may bring about a variety of remarks. Supporters of the populist style of the royal family tend to use skillfully with a positive connotation, while for the conservatives who hold that the populist behaviors detract from the dignity of the royal, skillfully is a derogatory term, specifically, a satire on Dianna, while unskillfully implies the sympathy for Prince Charles. In this context, the writer increases the meaning potential of the antonym unskillfully/ skillfully by constructing unconventional opposition, and turns over responsibility and right for the stance selection to readers. By contrast, the writer in example 10 explicitly shows his opposition to other products out of the motivation of drawing readers into his position.

Example 10: We lead, others copy.

We lead, others copy is the advertising slogan of Ricoh, which is greatly persuasive to readers. In this example, the interpersonal meaning comes from the unconventional oppositional relation constructed between we and others. The opposition between we and others is triggered by the parallel structure of the sentence and the opposition between the attitudinal meanings (Attitude-Appreciation-Valuation) of lead and copy. They are not conventional antonyms, but imply opposite attitudinal meaning, given that lead means the advance and innovation of technology while copy implies imitation and following, that is, the backward and obsolete technology. To sum up, in the above slogan, positive evaluation is projected on their own brand while negative comment is made on others. Through such an opposition of attitudinal meanings, the Ricoh highlights its advantages to draw the (potential) customers.

\section{Textual Meaning of Unconventional Opposition}

Textual function primarily deals with the realization of ideational meaning and interpersonal meaning in specific text. From writer's position, the textual meaning is realized by thematic structure; while from readers', it is represented by information structure. The construction of unconventional opposites is a process of language use driven by some kind of motivation of the writer and intertwined with the thematic structure and information structure of clause and the cohesion mechanism of the text, jointly realizing the textual meaning. 


\subsection{Unconventional Opposition, Thematic Structure and Information Structure}

Classification is a common strategy for elaborating in text. The subcategories are typically manifested as oppositional relation when the classification is conducted on the basis of dichotomy.

Example 11: Housing market is divided into primary market and secondary market. The former is the market of newly- developed commodity apartment, while the latter means the market of second-hand commodity market.

The first sentence in example 11 is a simple sentence. is divided into is a metalinguistic trigger of opposition that puts primary market and secondary market in opposition. The second is a compound sentence containing two clauses. The antonym newly-developed/ second-hand and the connective while further the construction of opposition between primary market and secondary market. Additionally, contrastive rhetoric is employed in the compound sentence in that the two sides with obvious difference, contradiction and opposition are put together to make a comparison and placed in contrastive relation (Mann \& Thompson, 1986).

In the process of classification, ideational relationship is realized by attributive possessive relational process or sequential relation, such as there are two kinds of noun phrase. The first is...; the second is... or contrastive relation as in example 11. From the rhetorical point of view, contrastive relation is superior to sequential relation, which can be substantiated by textual metafunction of language as follows. The first sentence in example 11 constructs primary market and secondary market as opposites and functions as the topic sentence in the discourse which can also be treated as a higher-level Theme: a hyperTheme, in that it elicits the theme of the following compound sentence. Furthermore, the tension produced by the opposition promotes the development of the text and forms a thematic progression patternparallel continuous progression, that is, two continuous progressions run in parallel. Specifically, the parallel continuous thematic progression produces two parallel information flows, and the progressive flows of new information and given information not only facilitate the demonstration of interpersonal meaning, but also bring forth aesthetic effect, thus promoting readers' understanding and drawing their favor.

The construction of unconventional opposition in example 11 demonstrates the readers a continuous information flow, while that in example 2 shows the opposite. Instead of resting at night triggering the opposite is a marked theme which signals new phases in a discourse and functions to scaffold discontinuity (Martin \& Rose, 2007: 192). Refraining from creating an information flow in which he serves as the theme and the negative emotion of the leading character as the rheme to provide new information, the writer inserts and foregrounds the daily schedule of ordinary people (resting at night) which discontinues the information flow in order to highlight the extreme distress of the leading character in the story.

\subsection{Unconventional Opposition and Discourse Cohesion}

Besides optimizing the thematic progression pattern and information structure, the constructed unconventional opposition contributes greatly to makes a more cohesive and 
coherent text. When nominal metalinguistic triggers of opposition such as difference, distinction, separation, change, contrast are used with pronouns this or these, the events or entities discussed above are constructed as opposites. The similarity of meaning between 'anaphora label' (Francis, 1994) realized by noun phrase and the foregoing, brings the ideational meaning of the foregoing into the transitivity system of what follows, which is a kind of structure adopted by the writer to support his argument and implies the writer's evaluation of the preceding part. Besides, 'anaphora label' serves as an important means of lexical cohesion in written discourse and is capable of organizing text by dint of topic switching and topic linking.

Example 12: Because of these differences in L1-L2 developmental patterns, lexical specificity training could have different effects in bilingual versus monolingual children (Janssen et al., 2015: 366).

From example 12, it can be inferred that the foregoing elaborates the developmental pattern of L1 and L2. The writer, by using metalinguistic trigger of opposition difference, constructs an oppositional relation between L1 and L2 developmental pattern. The anaphora these and the opposition trigger difference joint together to summarize the preceding content, lessening readers' burden of processing the foregoing details. What's more, the tension produced by the opposites helps to draw forth the new opposites bilingual and monolingual in what follows. As a result, the oppositions in the context are closely connected and coherent, making an organic entity.

\section{Conclusion}

This study illustrates the construction of unconventional opposition in discourse from the perspective of the metafunctions of Systemic Functional Linguistics, specifically, from the ideational, interpersonal and textual meaning.

In the aspect of ideational meaning, opposition triggers bring opposite into discourse, which either changes the transitivity structure of the clause by adding participants, or circumstantial elements which are familiar or known to the readers, or changes the logical semantic relation and extends the meaning of the main sentence. The construction of unconventional opposition contributes to readers' understanding of the concepts and events in discourse. On the level of interpersonal meaning, the negative structure and appraisal resources are employed by write as triggers to trigger oppositions and interact with readers. The negative structure helps to spotlight the stance of the writer by excluding the possible expectations of the readers to the proposition. In the appraisal system, the opposite attitudinal meaning is commonly used to construct opposites, to be specific, the writer can receive emotional resonance and align with the readers through the construction of opposites in the category of Affect; besides, the writer increases the meaning potential of the judgment resources by triggering opposition with the opposite attitudinal meaning in the category of Judgment; owing to implicit appraisal resources in the category of Appreciation, the writer guides the audience by evaluating the product based on popular values. On the level of textual meaning, 
the unconventional opposition helps to arrange the layout of text, adjust information flow and provide textual cohesion, thus showing the rhetorical effect of the text and facilitating readers' understanding and appreciation.

\section{References}

Bowles, M. A., \& Toth, P. D., \& Adams. R. J. (2014). A comparison of L2-L2 and L2-heritage learner interactions in Spanish language classrooms. The Modern Language Journal, 98(2), 497-517. https://doi.org/10.1111/modl.12086

Davies, M. (2013). Oppositions and Ideology in News Discourse. London: Bloomsbury Academic.

Eisenstein, J. (2015). Systemic patterning in phonologically motivated orthographic variation. Journal of Sociolinguistics, 19(2), 161-188. https://doi.org/.1111/josl.12119

Eskildsen, S. W., \& Wagner, J. (2015). Embodied L2 construction learning. Language Learning, 2, 268-297. https://doi.org/10.1111/lang.12106

Francis, G. (1994). Labelling Discourse: An Aspect of Nominal-group Lexical Cohesion. In Coulthard, M. (Ed.). Advances in Written Text Analysis (pp. 83-101). London: Routledge.

Givón, T. (1993). English Grammar: A Function-based Introduction. Amsterdam: John Benjamins Publication. p. 188.

Halliday, M. A. K. (1985). An Introduction to Functional Grammar. London: Arnold.

Halliday, M. A. K. (1994). An Introduction to Functional Grammar (2 ${ }^{\text {nd }}$ ed.). London: Arnold.

Halliday, M. A. K., \& Hasan, R. (1976). Cohesion in English. London: Longman Group. p. 4.

Halliday, M. A. K., \& Matthiessen, C. M. I. M. (2004). An Introduction to Functional Grammar ( ${ }^{\text {rd }}$ ed.). London: Arnold.

Hu, Z. L. et al. (2008). An Introduction to Systemic-functional Linguistics. Beijing: Peking University Press.

Janssen, C. et al. (2015). Lexical specificity training effects in second language learners. Language Learning, 65(2), 358-389. https://doi.org/10.111/lang.12102

Jeffries, L. (2010). Opposition in Discourse: The Construction of Oppositional Meaning. London: Continuum.

Jones, S. (2002). Antonymy: A Corpus-based Perspective. London: Routledge. p. 49.

Lee, S. (2015). Creaky voice as a phonational device marking parenthetical segments in talk. Journal of Sociolinguistics, 19(3), 275-302. https://doi.org/10.1111/josl.12123

Mann, W. C., \& Thompson, S. A. (1986). Relational propositions in discourse. Discourse 
Processes, 9(1), 57-90.

Martin, J. R. (2001). Beyond Exchange: Appraisal Systems in English. In Hunston, S., \& Thompson, G. (Eds.), Evaluation in Text (pp. 142-175). Oxford: Oxford University Press.

Martin, J. R., \& Rose, D. (2007). Working with Discourse. London: Continuum.

Martin, J. R., \& White, P. R. (2005). The language of Evaluation: Appraisal in English. London: Continuum.

Mathesiue, V. (1939). On the so-called actual bipartition of the sentence. Slovo a slovesnos, 7(5), 171-174.

Miao, X. W. (2011). Textual functions of negative constructions. Foreign Language Teaching and Research, 2, 62-71.

Palmer, D. et al. (2014). Reframing the debate on language separation: toward a vision for translanguaging pedagogies in the dual language classroom. The modern Language Journal, 98(3), 757-772. https://doi.org/10.1111/modl.12121

Shakespeare, W. (2003). A Midsummer Night's Dream. Cambridge: Cambridge University Press. p. 19.

Thompson, G. (2000). Introducing Functional Grammar ( $2^{\text {nd }}$ ed.). London: Arnold/ Beijing: Foreign Language Teaching and Research Press.

Xiao, Y., \& Wong, K. F. (2014). Exploring heritage language anxiety: a study of Chinese heritage language learners. The Modern Language Journal, 98(2), 589-611. https://doi.org/10.1111/modl.12085

\section{Copyright Disclaimer}

Copyright for this article is retained by the author(s), with first publication rights granted to the journal.

This is an open-access article distributed under the terms and conditions of the Creative Commons Attribution license (http://creativecommons.org/licenses/by/3.0/). 